\title{
GROWTH AND DEVELOPMENT OF FIMBRISTYLIS MILIACEA (L.)VAHL
}

\author{
MAHFUZA BEGUM ${ }^{1 *}$, ABDUL SHUKOR JURAIMI ${ }^{2}$, \\ RAJAN AMARTALINGAM ${ }^{2}$, SYED OMAR BIN SYED RASTAN ${ }^{3}$ \\ AND AZMI BIN MAN ${ }^{4}$
}

\author{
${ }^{1}$ Department of Agronomy, Bangladesh Agricultural University, Bangladesh \\ ${ }^{2}$ Department of Crop Science, Faculty of Agriculture, UPM, 43400 Serdang, Malaysaia \\ ${ }^{3}$ Department of Land Management, Faculty of Agriculture, UPM, 43400 Serdang, Malaysia \\ ${ }^{4}$ MARDI, Pulau Pinang, Malaysia
}

\begin{abstract}
This experiment was conducted in the glasshouse of Universiti Putra Malaysia, to determine the growth and development of Fimbristylis miliacea (L.) Vahl. Twenty F. miliacea seeds were surface sown in ten plastic buckets of $18 \mathrm{~cm}$ diameter filled with $3 \mathrm{~kg}$ soil. After germination only one plant/bucket was retained. Time of first seedling emergence, time and number of leaves appearing until first tiller formation, time of tiller formation, first inflorescence, the first 10 inflorescences appearance and their maturity were recorded for each plant. Plant height and the number of inflorescence per plant was recorded weekly for up to 4 months after sowing. The first ten inflorescences for each plant were tagged after emergence, subsequently mature inflorescences were collected and the numbers of spikelets/inflorescence, seeds/inflorescence, seeds/ plant and 1000 seed weight were determined. Statistical analysis was performed as complete randomized design on weekly observed plant height and inflorescence number using the SAS statistical software and means were tested using Tukey's studentized range test at the $5 \%$ level of probability. Fimbristylis miliacea seedlings emerged at 3 days after planting of seeds. Approximate times required for the sequential production of 10 leaves, tillers, first 10 inflorescence and their maturity were 28 days after emergence (DAE), 35 DAE, 49 DAE, 63 DAE, respectively. Plant height increased rapidly from 3-8 WAE and maximum plant height $(64.05 \mathrm{~cm})$ was attained at 10 WAE. This species had three important growth stages: a slow growth stage during the first 4 weeks after emergence (WAE); a rapid growth stage from 4-9 WAE; and finally, a maximum growth stage from 9-17 WAE. Within this first 4 weeks after emergence would be the most appropriate time for controlling this species with early post-emergence herbicides. Each $F$. miliacea plant produced on average of 2.3 tillers/plant and a total of 134 inflorescences, with 84 inflorescences/plant ripening within this period. Each inflorescence comprised 48 spikelets with 511 seeds and matured after 3 weeks of emergence. Total seeds/plant and 1000 seed weight were 42275 and $0.035 \mathrm{~g}$, respectively. Time required for seed ripening was 76 days after emergence.
\end{abstract}

Key words: life cycle, growth, development, Fimbristylis miliacea

*Corresponding author: mafupaz@hotmail.com 


\section{INTRODUCTION}

Species differ substantially in life form and timing of stages of development and reproduction. Each of these processes occurs at a measurable, requisite rate. Successful individuals grow rapidly or largely, develop through the various stages of their life cycle, and eventually are replaced in the environment by their progeny (Radosevich et al.1997). The components of the life cycle such as timing of germination, seedling emergence, adult survival, age of flowering, and seed numbers are pre-requisites to be determined during the life span of the plant (Sabrig 1980; Silvertown and Doust 1993). The plant developmental phases are fundamental to the understanding of plant function, that is, the manner of interaction within the environment.

Fimbristylis miliacea is a serious weed in ricefields in South-East Asia (Moody 1989; Smith 1983). In spite of the importance of this weed little is known about the species growth and development. In several annual and perennial weed species, studies on growth and developmental characteristics have increased the understanding of the weed's morphological characteristics that aid in success, and or exploited in a control program. Smith and Fick (1938) studied the life history of purple nutsedge (C. rotundus) and related several growth characteristics to possible control methods. They found that effective control can be obtained if control measures are taken early in the life cycle of the plant. McWhorter (1961) conducted similar experiments with johnsongrass [(Sorgbum halepense) (L.) Pers.]. They concluded that eradicating johnsongrass plants must be accomplished before new rhizomes are formed (6 to 8 weeks) to be effective. Chandler et al. (1977) stated that in moonflower weed the total number of seed per pods and seeds produced per plant were 2730 and 9350 , respectively, with peak production occurring 5 through 7 weeks after initiation of anthesis. Controlling this weed within this period is to eliminate seed production. Thus, the time of flowering and seed production are thus important to know.

Growth and development study have been observed in several weed species such as Echinochloa crus-galli (Azmi 1994; Itoh 1991; Arifin 2004), Leptochloa chinensis (Pane 1997), Ischaemum rugosum (Bakar and Nabi 2003), Cyperus esculentus and C. rotundus (Williams 1982). Even though, biological study of $F$. miliacea has been reported to some extent by Burkill (1935) and Holm et al. (1977). But, in recent past growth and development studies on F. miliacea have not been reported. An understanding of the phenology of a weed is important for developing strategies for its control. Differences in the behavior of species at each stage reveal to differences in susceptibility to control by a particular approach. Information on occurrence of emergence, leaf formation, tillering, flowering, fruiting and other developmental processes would facilitate the timing of effective control measures. Therefore, the study on the growth and development of F. miliacea was undertaken with the objectives of (i) to determine F. miliacea growth characteristics from seed germination to seedling establishment and subsequent seed production and (ii) to quantify the time of occurrence of all growth-developmental stages of Fimbristylis miliacea. 


\section{MATERIALS AND METHODS}

The experiment was conducted in the glasshouse at Universiti Putra Malaysia, from November 2003 to March 2004. Seeds of F. miliacea were collected from a ricefield at the Malaysian Agricultural Research Development Institute (MARDI) research station, in Bertam, Pulau Pinang on August 2003. The soil used was collected from a Tanjung Karang ricefield, which was a silty clay (49.71\% clay, $49.56 \%$ silt and $0.73 \%$ sand) of Bakau series (Typic Hydraquents) with pH 4.98. Twenty seeds were surface sown in $18 \mathrm{~cm}$ diameter plastic buckets filled with $3 \mathrm{~kg}$ soil. Ten buckets were used for this experiment. After germination, only one plant/bucket was retained. All other seedlings were removed as soon as they emerged. One third of the urea, whole triple super phosphate (TSP) and muriate of potash (MOP) were applied as basal fertilizer treatments at rates equivalent to 370,167 and $250 \mathrm{~kg} / \mathrm{ha}$, respectively. Another two thirds of the urea was applied at 35 and 55 days after sowing. Based on area basis each bucket received a total of $0.93 \mathrm{~g}$ urea, $0.42 \mathrm{~g}$ TSP and $0.63 \mathrm{~g}$ MOP. The buckets were irrigated with tap water and maintained at saturation condition. Malathion was applied when required to control insect pests.

Time of first seedling emergence, time and number of leaves appearing until first tiller formation, time of tiller formation, and first inflorescence appearance were recorded for each plant. Plant height was measured weekly from the soil surface to the tip of the leaf. Time of appearance of the first 10 inflorescences and their maturity was also recorded to determine the average total time to maturity of Fimbristylis miliacea. The number of inflorescence per plant was recorded weekly for up to 4 months after sowing to correlate with the life span of cultivated rice.

The first ten inflorescences for each plant were tagged when they emerged. These inflorescences were collected when mature and the numbers of spikelets/inflorescence were determined. These ten inflorescences were then dried for 1 week, threshed by hand and the seeds separated by winnowing. The seeds were weighed and number of seeds per inflorescence were estimated using 1000 seed weights. The number of seeds/ inflorescence was derived from the average number of seeds/10 inflorescence per plant which was as follows (Charotte et al. 1990):

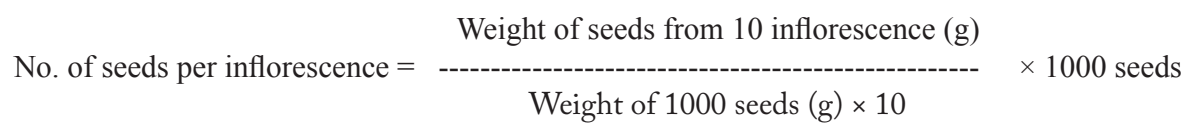

Thus total seeds per plant were estimated from the number of seeds per inflorescence multiplied by the number of matured inflorescence per plant. Statistical analysis was performed on weekly observed plant height and inflorescence number using the SAS statistical software and means were tested using Tukey's studentized range test at the $5 \%$ level of probability. 


\section{RESULTS AND DISCUSSION}

\section{Growth characteristics of Fimbristylis miliacea}

Growth rate as measured by increases in plant height over time was significant. Initially, the plants were stunted and increase in plant height was slow for the first 2 weeks (Figure 1).

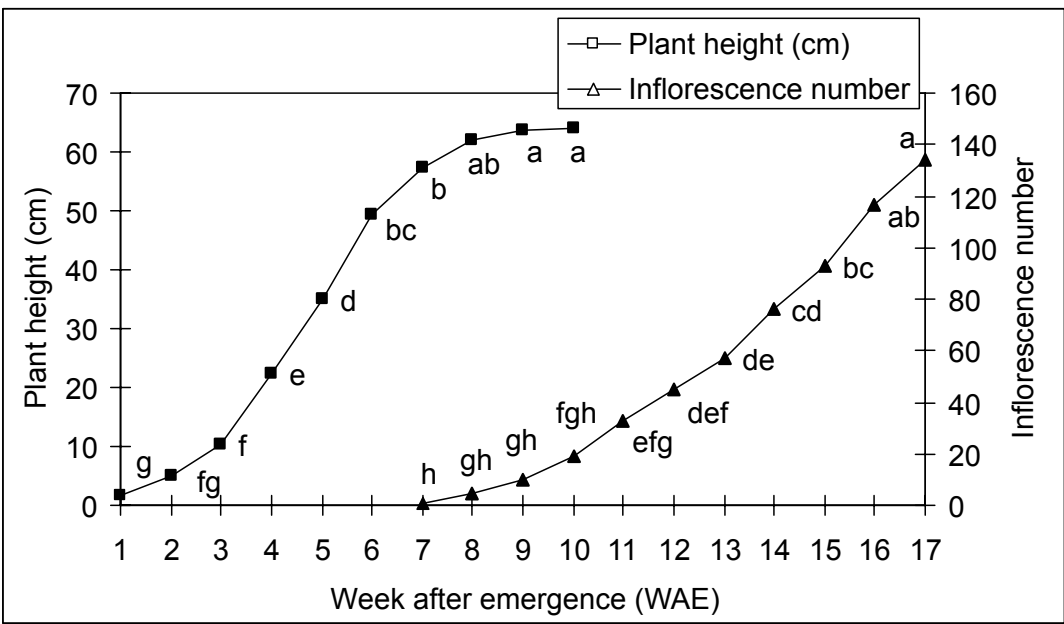

Figure 1. Weekly measured plant height and inflorescence number of $F$. miliacea (Means within week after emergence (WAE) with same alphabets are not significantly different at $\mathrm{P} \geq 0.05$ (Tukeys Test))

However, at the $3^{\text {rd }}$ week after emergence, a significant rapid increase in plant height $(10.5 \mathrm{~cm})$ was observed and significantly higher weekly increasing rate was observed for up to 8 weeks. During this time the plant reached $96.57 \%$ of its maximum height. At 10 weeks after emergence the plant reached maximum height $(64.05 \mathrm{~cm})$ (Figure 1). Beyond this period, height did not increase due to onset of leaf tip senescence. A similar pattern was obtained in L. chinensis, where for the first 20 days, plants grew slowly, while during 20 - 50 days after sowing (DAS) the plant height increased rapidly to $100 \mathrm{~cm}$ and with increases of 2-3 cm/day. At 70 DAS the plants reached maximum height (Pane 1997). Pennisetum polystachyon which grows to a height of $201 \mathrm{~cm}$, also showed slow initial growth for up to 8 weeks followed by a rapid increase in height at 14 weeks, resulting from the elongation of the internodes at the onset of reproduction (Fernandez 1982). In contrast the fast growing weed species, purple moonflower reached $85 \%$ of its height within by 4 weeks after emergence (Chandler et al.1977) and Scirpus maritimus increased it height at the rate of $2.7 \mathrm{~cm} /$ day during the first 40 days of growth (Visperas and Vergara 1978). Differences in plant height are an important 
Growth and development of Fimbristylis miliacea (L.) Vahl - Mahfuza Begum et al.

criteria determining species competitiveness as well as to timing of control measures. Growth studies on giant burred (Sparganium eurycarpum Englem.), a perennial weed in annual wild rice, demonstrated that during early season growth a height difference existed between the weed and the crop which allowed for selected herbicide application (John and Ervin 1990). In some crops, efficient and safe use of herbicides, requires a height differential between the crop and the weed in order that the weed can be sprayed with minimal contact with crop foliage.

Tiller formation in F. miliacea was 1-4 per plant and average tiller production was 2.3 per plant (Table 1). Total production of inflorescences/plant was 134 within the 4-month period (Table 1). Positive correlation was found between tiller numbers and number of inflorescence produced (Figure 2). When tiller production increased from 1 to 4 , the inflorescence production showed a linear increase from 67 to 210 . Weekly increases in inflorescence production were significant (Figure 1). The lowest inflorescences number was observed at 7-week after emergence (WAE). Inflorescence number then gradually increased from 10 to $16 \mathrm{WAE}$. There were no significant differences between 16 and 17 WAE. During the 4 months period a total of 84 inflorescences/plant matured, and percentage of ripened inflorescence was $63.22 \%$ (Table 1)

Table 1. Growth characteristics of F. miliacea plants

\begin{tabular}{cc}
\hline Growth parameter & Mean \pm SE \\
\hline Plant height $(\mathrm{cm})$ & $64.05 \pm 6.07$ \\
No. of tillers/plant & $2.3 \pm 0.483$ \\
No. of produced inflorescence/plant & $133.8 \pm 42.39$ \\
No. of ripened inflorescence/plant & $84 \pm 25.33$ \\
\% ripened inflorescence/plant & $63.22 \pm 4.57$ \\
No. of spikelets/inflorescence & $48.96 \pm 6.82$ \\
Seed no./inflorescence & $511 \pm 76$ \\
Seed weight/plant (g) & $1.374 \pm 0.330$ \\
Seed no./plant & $42275 \pm 6696$ \\
1000 seed weight $(\mathrm{g})$ & $0.035 \pm .00215$ \\
\hline
\end{tabular}

Each inflorescence was laddered with 49 spikelets and 511 seeds (Table 1). The total seed and 1000 seeds weight were $1.37 \mathrm{~g}$ and $0.035 \mathrm{~g}$, respectively. Total number of seed/plant was 42 276. Although in the Phillipines Holm et al. (1977) observed that seed production of each F. miliacea plant was 10000 . Actually, seed output is a highly plastic character and is responsive to local growing conditions particularly nutrient availability, day length, and plant density. Echinochloa crus-galli seed production per plant ranged from $10776-47850$ (Itoh 1991). Whereas, Azmi and Itoh (1991) reported that the 
E. crus-galli complex produced less seeds 12129 seeds/plant in the ricefield due to the impact of competition with the direct-seeded crop. Most annual weeds produce a few thousand seeds per individual when growing with minimal competition, though some produce 10000 to 25000 seeds per plant (Salisbury 1942), while others like E. crusgalli under some situations may produce over 100000 seeds per plant (Young 1986; Norris 1992). A few annuals (e.g. Varonica hederifolia) produce fewer than 100 seeds per individual plant (Salisbury 1942; Boutin and Harper 1991). The number of seeds produced by a plant is the product of three variables: (i) the size of the plant (ii) the proportion of photosynthate allocated to seeds, and (iii) the mean seed weight. The seed production capacity of weeds varies greatly both within and between species. Williams (1982) reported that the growth of C. esculentus and C. rotundus as characterized by their total dry weight, inflorescence dry weight, root and rhizome dry weight and number of shoots per pot was similar, but they differed in the manner in which the dry weight was partitioned to reproductive structures. Each species partitioned less than $2 \%$ of its dry weight into floral formation. However, C. esculentus partitioned only $38 \%$ of its dry weight to tubers, whereas C. rotundus partitioned 50\% of its dry weight to fewer and larger tubers. In the case of $I$. rogusum, seeds/spike, seed weight/plant (g) and seed number/plant and 1000 seed weight (g) was 57, 24.5, 6000 and 4, respectively (Bakar and Nabi 2003), which indicates much bigger seed size and lower seed number/plant than Fimbristylis miliacea.

\section{Growth stages of Fimbristylis miliacea}

Emergence of $F$. miliacea started at 3 days after planting of seeds (Table 2). Approximate times required for the sequential production of leaves, tillers, first 10 inflorescence and their maturity are shown in Table 2 and Figure 2. At 7 days after emergence (DAE) the plants were at the 3-4 leaf stage.

Table 2. Approximate time required for seedling emergence, leaf, tiller and inflorescence formation and inflorescence ripening

\begin{tabular}{cc}
\hline Growth parameter & Mean time (Days after seedling emergence) \pm SE \\
\hline $1^{\text {st }}$ seedling emergence & $3 \pm 0$ \\
$2^{\text {nd }}$ leaf formation & $2.82 \pm 0.40$ \\
$3^{\text {rd }}$ leaf formation & $5.27 \pm 0.65$ \\
$4^{\text {th }}$ leaf formation & $7.65 \pm 0.84$ \\
$5^{\text {th }}$ leaf formation & $10.32 \pm 0.95$ \\
$6^{\text {th }}$ leaf formation & $12.18 \pm 0.75$ \\
$7^{\text {th }}$ leaf formation & $14.5 \pm 0.58$ \\
$8^{\text {th }}$ leaf formation & $18.33 \pm 0.82$ \\
\hline
\end{tabular}


Growth and development of Fimbristylis miliacea (L.) Vahl - Mahfuza Begum et al.

Table 2. Continued

\begin{tabular}{cc}
\hline Growth parameter & Mean time (Days after seedling emergence) \pm SE \\
\hline $9^{\text {th }}$ leaf formation & $20.67 \pm 0.52$ \\
$10^{\text {th }}$ leaf formation & $25.0 \pm 1.05$ \\
$11^{\text {th }}$ leaf formation & $29.0 \pm 0.82$ \\
$12^{\text {th }}$ leaf formation & $33.43 \pm 1.72$ \\
$1^{\text {st }}$ tiller formation & $35.2 \pm 3.68$ \\
$2^{\text {nd }}$ tiller formation & $40.41 \pm 3.36$ \\
$3^{\text {rd }}$ tiller formation & $41.57 \pm 3.36$ \\
$4^{\text {th }}$ tiller formation & $42 \pm 0$ \\
$1^{\text {st }}$ inflorescence & $49 \pm 2.78$ \\
$5^{\text {th }}$ inflorescence & $57 \pm 2.70$ \\
$10^{\text {th }}$ inflorescence & $63 \pm 1.94$ \\
Inflorescence ripening (after & $17.90 \pm 1.62$ \\
formation) & $76 \pm 6.71$ \\
Inflorescence ripening (after & \\
emergence) &
\end{tabular}

At 14 DAE the plant had 6-7 leaves and within 28 DAE the plants had reached the 10-11 leaf stage. At 4 weeks (28 days) the plant started to produce tillers. Observation at 35 DAE showed that the plant produced the first tiller from the 5-7 leaf node while at the 11-12 leaf stage. The first 4-6 leaves senesced before first tiller formation. Obviously, leaf formation with time varies from species to species. Pane (1997) observed that L. chinensis produced 4-6 leaves at 20 DAS and produced 2-3 tillers with 1-3 inflorescences at 30 DAS. Whereas, a very fast growing species like E. crus-galli produced the first 2 to 3 leaves within 4 to 7 days after emergence, and seedlings started producing tillers at 14-18 days after emergence (Itoh 1991; Azmi et al. 1995).

Tiller formation stopped at the onset of the reproductive stage. All tiller formation occurred 42 days ( 7 weeks) after seedling emergence, followed by the emergence of $1^{\text {st }}$ inflorescence within one week, whereas in I. rugosum, production of new tillers ceased 3-4 weeks after floral initiation, but resumed at 16 weeks when most of the spikes had ripened. New tillers were usually unbranched, reduced in height with less seeds/spike (Bakar and Nabi 2003). Azmi et al. (1995) reported that E. crus-galli headed at 44-55 DAE.

In this study, F. miliacea produced 10 inflorescences within 63 DAE (9 weeks). The inflorescence matured after 18 DAE ( 3 weeks) of emergence (Table 2 and Figure 2). Total time required for emergence to seed maturation was 76 days. In I. rugosum approximately 4 weeks was required for spikes to ripen (Bakar and Nabi 2003). In L. chinensis, panicles ripened at 50-60 days after seeding (Pane,1997), while $42-56$ days 
were required to heading and 89 - 98 days were required for maturity in E. crus-galli (Itoh 1991; Arifin 2004). In this study, 80\% of F. miliacea leaves were dead at harvest (120 days). The time required to reach reproductive maturity in weeds varies considerably and often similar to the companion crop or sometimes considerably shorter. In the tropics, weed life cycles may be extremely short. Echinochloa colona, Setaria verticillata and D. aegyptium approach flowering in 30-45 days whilst Rottboellia cochinchinensis produced mature seeds within 50 days of establishment (Fisher et al.1985). Similar short duration life cycles may also be observed in weeds of temperate latitudes (e.g. Capsella bursa-pastoris L.), but weeds of major importance tend to have an extended growing season approaching to at least 6 months. From comparative studies, $M$. vaginalis, $C$. difformis, F. miliacea and E. glabrescens have been reported to begin flowering even when plants have achieved less than $10 \%$ of their maximum biomass, with seed production continuing for more than four months (Kim and Moody 1989).

The growth stages of $F$. miliacea could be classified into 3 stages (a) slow initial growth stage, from emergence to 4 weeks after emergence (WAE), (b) active growth stage, from 4 to 9 WAE, (c) maximum growth stage, from 9 to 17 WAE (Figure 2).

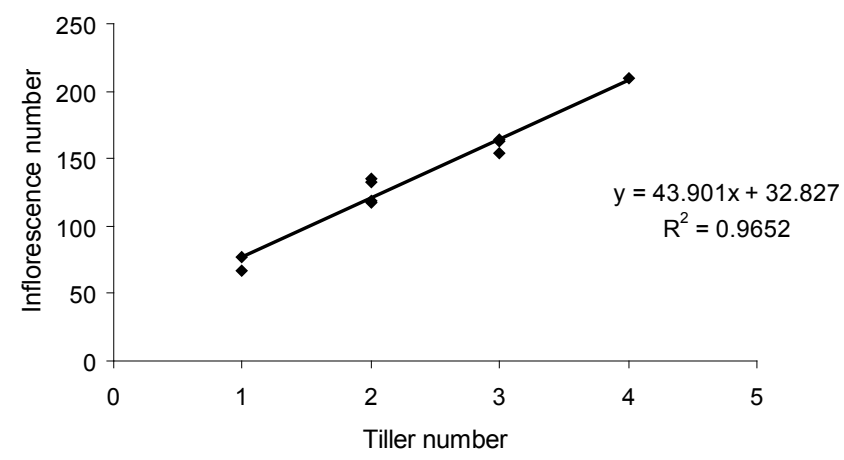

Figure 2. Growth and development of Fimbristylis miliacea (L.) Vahl

In the first 4 weeks after emergence, the plants grew slowly and attained 10-11 leaf stage. This would be the most appropriate time for controlling this species with early post emergence herbicides. During the active growing period plant height was maximum, tiller formation ceased and the plant produced up to 10 inflorescences. In annual plants the foregoing phases of the life cycle follow one another in uninterrupted sequence (Larcher 1975). Beyond 10 WAE F. miliacea reached maximum flowering stage, and leaves, and some parts of flowering stalks and inflorescences gradually became senescent. The phase of seed production in annual plants is often associated with the rapid death of leaves and the appearance of symptoms usually associated with mineral deficiency as if the leaves have been "sucked dry" of some essential nutrient which has been trans-located to meet the greater needs of the seeds. The evolutionary development of annual plants have major activities that require resource allocation, i.e. starting from 
seed, and continuing with the processes of dispersal, dormancy, germination, seedling establishment, vegetative phase, resource capture, growth, flowering, seed production and lastly seed maturity (Radosevich and Holt, 1984). Evidently, F. miliacea also has the same growth pattern. Holm et al.(1977) repeatedly emphasizes the ability of weeds to compete against crop species and most of the weeds allocate a large proportion of resources to seed production. Thus importance of early weed control for optimum crop production has been recognized for many years by agronomists. Perhaps the basis for this view is the morphological and physiological adaptations through common evolutionary origin among weed species and crops that cause early onset of competition. Species growth characteristics provide an indication of competitive ability, and understanding weed seedling growth rates is also important when considering weed management strategy that includes the use of herbicides. Improper application timing of herbicide can result in poor weed control and the need for remedial treatment.

\section{CONCLUSIONS}

Fimbristylis miliacea seed emergence occurred 3 days after sowing. Plant height increased rapidly from 3-8 WAE and maximum plant height of $64.05 \mathrm{~cm}$ was attained at 10 WAE. First tiller formation was at 11-12-leaf stage after 4 WAE and the range of tiller production was 1-4 (average 2.3) per plant. Inflorescence production was proportional to number of tillers produced. Total numbers of 134 inflorescences/ plant were produced, of which the ripened inflorescences/plant and seeds/plant was 84 and 42 276, respectively. One thousand seed weight was $0.035 \mathrm{~g}$. This species has three important growing stages: a slow growth stage during the first 4 WAE; a rapid growth stage that generally took place from 4-9 WAE; and finally, a maximum growth stage from 9-17 WAE. The inflorescences generally developed 7-8 WAE and subsequently matured 11-12 WAE. The time requirement for inflorescence maturation was 3 weeks after inflorescence emergence. Agricultural weeds generally share certain properties, including small seed size, high relative growth rate, low early absolute growth rate, tolerance to stress and high reproductive capacity. These differences form the basis for a variety of weed management tactics for successful control. Thus, growth and development study of a specific weed species is an organizing principle for the integration of weed management practices.

\section{ACKNOWLEDGMENTS}

This study was a part of $\mathrm{Ph} \mathrm{D}$ research work, funded as postgraduate fellowship sponsored by Third World Organization for Women in Science (TWOWS), Trieste, Italy. All other research facilities were provided by the IRPA project No. 01-02-040778-PR0068/05-05, Universiti Putra Malaysia. 
BIOTROPIA VOL.15 NO. 1, 2008

\section{REFERENCES}

Arifin, T. 2004. Morphological and molecular variability amongs ecotypes of barnyardgrass (Echinochloa crus-galli var. crus-galli (L.) Beauv) : implication for biocontrol. Ph. D. Thesis. Universiti Putra Malaysia. p. 4.1- 4.28 .

Azmi, M. 1994. Biology and control of Echinochloa crus-galli (L.) Beauv. in direct seeded rice. Ph. D. Thesis, School of Biological Sciences, Universiti Sains Malaysia. p. 333.

Azmi, M. and K. Itoh. 1991. Echinochloa crus-galli complex. In : Life Cycles of Rice Field Weeds and Their Management in Malaysia. Tropical Agriculture Research Centre, ed. Itoh, K., Tsukuba, Japan, p. 17-27.

Azmi, M., M.Mashhor., K. Itoh and H.Watanabe. 1995. Life cycle and seed longevity of Echinochloa crus-galli complex in direct-seeded rice in Malaysia. In: Proceeding of $15^{\text {th }}$ Asian Pacific Weed Science Conference, p. 505-511. Tsukuba, Japan.

Bakar, B.H. and L.N.A. Nabi. 2003. Seed germination, seedling establishment and growth patterns of wrinklegrass (Ischaemum rugosum Salisb.). Weed Biol. and Manag., 3:8-14.

Boutin, C. and J. L. Harper. 1991. A comperative study of the population dynamics of five species of Veronica in natural habitates. J. Ecol., 79: 199-221.

Chandler,J.M., R.L. Munson, and C.E. Vaughan. 1977. Purple Moonflower: Emergence, growth, reproduction. Weed. Sci., 25(2): 163-167.

Charrote, V.E., L.L. Edith, L.M. Timothy and L.M. Janis. 1990. Growth and development of wild-proso millet (Panicum miliaceum) biotypes. Weed Tech., 4: 415-419.

Fisher, H.H., F. Lopez, L.Margate, P. Elliot and L. Burrill. 1985. Problems in control of Rottboellia exaltata in maize in Bukidnon province, Mindanao, Philippines. Weed Res., 25:93-102.

Holm, L.G., D.L. Pluknett, J.V. Pancho and J.P. Herberger. 1977. The World's Worst Weeds: Distribution and Biology. The University Press of Hawaii. Honolulu. p. 273-279.

Itoh, K. 1991. Life Cycles of Rice Field Weeds and Their Management in Malaysia. Tropical Agriculture Research Centre, Tsukuba, Japan, p. 92.

John, W.L. and A.O. Ervin. 1990. Growth and development of Giant Burreed (Sparganium eurycarpum). Weed Tech., 4:849-854.

Kim, S.C. and K. 1989. Adaptation Moody, strategy and seed production of rice and weed species. Korean J. Weed Sci., 12:183-200.

Larcher, W. 1975. Physiological plant ecology. Springer-Verlag. New York. p.252.

McWhorter, C.G. 1961. Morphology and Development of Johnsongrass Plants from Seeds and Rhizomes. Weeds, 9:558-562.

Moody, K. 1989. Weeds reported to occur in rice in South and Southeast Asia. In: Weeds reported in South and Southeast Asia. International Rice Research Institute. Los Banos, Laguna, P.O Box 933, 1099 Manila, Philippines, pp. 1-80.

Norris, R.F. 1992. Relationship between inflorescence size and seed production in barnyard grass (Echinochloa crus-galli). Weed Sci., 40: 74-78.

Pane, H. 1997. Studies on ecology and biology of Red sprangletop [Leptochloa chinensis) (L.) Nees] and its management in direct-seeded rice. Ph. D. Thesis. Universiti Sains Malaysia. pp. 1-235.

Radosevich, S.R. and J.S. Holt. 1984. Weed Ecology: Implications for Vegetation Management. John Wiley \& Sons. New york. p. 265. 
Growth and development of Fimbristylis miliacea (L.) Vahl - Mahfuza Begum et al.

Sabrig, O.T. 1980. Demography and evolution in plant populations. Botanical Monogr. Vol. 15. Oxford. Blackwell Sci. Pub. p.222.

Salisbury, E.J. 1942. The reproductive capacity of plants. London: Bell.

Silvertown, J.W. and J.L. Doust. 1993. Introduction to plant population biology. Oxford. UK. Blackwell Sci. Pub. p. 210.

Smith, E.V. and G.L. Fick 1938. Nut Grass Eradication Studies: I. Relation of the life history of Nut Grass, Cyperus rotundus L., to Possible Methods of Control. J. Am. Soc. Agron. 10:107-113.

Smith, Jr.R.J. 1983. Weeds of major economic importance in rice and yield losses due to weed competition. In : Proceedings of Conference on Weed Control in Rice. International Rice Research Institute. Los Banos, Laguna Philippines. pp. 19-36.

Visperus, R.M. and B.S. Vergara. 1978. Autecology of Scirpus maritimus L. growth characteristics and competition with rice. Philip. Weed Sci. Bull., 3: 1-13.

Williams, R.D. 1982. Growth and reproduction of Cyperus esculentus L. and Cyperus rotundus L. Weed Res., 22: $149-154$.

Young, F.L. 1986. Russian thistle (Salsola iberica) growth and development in wheat (Triticum aestivum). Weed Sci., 34: 901- 905. 